\title{
Correction to: A study protocol for the development of a multivariable model predicting 6- and 12-month mortality for people with dementia living in residential aged care facilities (RACFs) in Australia
}

Ross Bicknell ${ }^{1 *}$, Wen Kwang Lim¹, Andrea B. Maier ${ }^{1,2}$ and Dina LoGiudice ${ }^{1}$

Correction to: Diagn Progn Res 4, 17 (2020)

https://doi.org/10.1186/s41512-020-00085-0

Following publication of the original article [1], the authors identified an error in the author name of Dina LoGiudice.

The incorrect author name is: Dina LoGiuidice.

The correct author name is: Dina LoGiudice.

The author group has been updated above and the original article [1] has been corrected.

\footnotetext{
Author details

'Department of Medicine and Aged Care, @AgeMelbourne, Melbourne Health-Royal Melbourne Hospital, University of Melbourne, 6 North Main Building, Royal Melbourne Hospital, 300 Grattan Street, Parkville, Victoria 3050, Australia. ${ }^{2}$ Department of Human Movement Sciences,

@AgeAmsterdam, Amsterdam Movement Sciences, Vrije Universiteit

Amsterdam, Amsterdam, The Netherlands.
}

Published online: 16 April 2021

\section{Reference}

1. Bicknell R, Lim WK, Maier AB, LoGiudice D. A study protocol for the development of a multivariable model predicting 6 - and 12-month mortality for people with dementia living in residential aged care facilities (RACFs) in Australia. Diagn Progn Res. 2020;4(1):17. https://doi.org/10.1186/ s41512-020-00085-0.

\footnotetext{
The original article can be found online at https://doi.org/10.1186/s41512020-00085-0.

* Correspondence: Ross.Bicknell@mh.org.au

'Department of Medicine and Aged Care, @AgeMelbourne, Melbourne Health-Royal Melbourne Hospital, University of Melbourne, 6 North Main Building, Royal Melbourne Hospital, 300 Grattan Street, Parkville, Victoria 3050, Australia

Full list of author information is available at the end of the article
}

(C) The Author(s). 2021 Open Access This article is licensed under a Creative Commons Attribution 4.0 International License, which permits use, sharing, adaptation, distribution and reproduction in any medium or format, as long as you give appropriate credit to the original author(s) and the source, provide a link to the Creative Commons licence, and indicate if changes were made. The images or other third party material in this article are included in the article's Creative Commons licence, unless indicated otherwise in a credit line to the material. If material is not included in the article's Creative Commons licence and your intended use is not permitted by statutory regulation or exceeds the permitted use, you will need to obtain permission directly from the copyright holder. To view a copy of this licence, visit http://creativecommons.org/licenses/by/4.0/. 